\section{Analisis Pengaruh Kualitas Pelayanan Terhadap Kepuasan Masyarakat Di Desa Paulan, Colomadu, Karanganyar}

\author{
Ana Mayasari \\ STIA-ASMI Solo \\ mayasariana92@email.com
}

\begin{abstract}
Abstrak
Kualitas Pelayanan terhadap kepuasan masyarakat sangatlah penting, begitu juga di Kantor Desa Paulan Kecamatan Colomadu Karanganyar. Teknik analisa menggunakan analisis regresi linier sederhana, uji t, dan koefisien determinasi $\left(\mathrm{R}^{2}\right)$. Hasil analisa bahwa kualitas pelayanan yang menyangkut aspek ketepatan waktu dalam pelayanan, akurasi dalam pelayanan, kesopanan dan keramahan pegawai, dan kenyamanan terbukti mempunyai pengaruh positif dan signifikan terhadap kepuasan masyarakat yang menggunakan pelayanan yang ada di Kantor Desa Paulan Kecamatan Colomadu Kabupaten Karanganyar. Dengan besarnya nilai $t_{\text {tabel }}(7,542>1,998)$ dan signifikan lebih kecil dari $0,05(0,000<0,05)$. Proporsi pengaruh kualitas pelayanan terhadap kepuasan masyarakat yang menggunakan pelayanan yang ada di Kantor Desa paulan Kecamatan Colomadu Kabupaten Karanganyar sebesar $47,4 \%$, sedangkan sisanya sebesar 52,6\% dipengaruhi oleh variable lain selain kualitas pelayanan seperti keberadaan kantor, sarana dan prasarana penunjang pelayanan dan sebagainya.
\end{abstract}

\section{Kata Kunci Kualitas pelayanan, Kepuasan Masyarakat}

\section{PENDAHULUAN}

Kebijakan desentralisasi sesuai UU No. 32 tahun 2004 (www.dpr.go.id, 2004)(Izudin, 2019)(Yayat, 2017) merupakan jawaban atas kegagalan sistem sentralistik pada masa Orde Baru. Pemerintah harus berusaha untuk selalu dapat memberikan pelayanan bagi masyarakat yang lebih baik (Pendayagunaan \& Negara, 2004)(Sukma, 2015)(Hermawan, Hakim, \& Hutagaol, 2016)(Wardani, 2017). Permasalahan tentang pelayanan public masih banyak kendala dikarenakan kurangnya kesadaran pemerintah akan peran dan fungsi mereka (Izudin, 2019)(Sinaga \& Hidayat, 2016)(Egaliter, 2019). Pemerintah daerah seharusnya merupakan motor dalam pemberian pelayanan public. Peran pemerintah daerah sebagai Public Relations merupakan upaya untuk dapat memberikan pelayanan publik(Egaliter, 2019)(Wardani, 2017). Banyak pandangan bahwa masyarakatlah yang merupakan konsumen yang membutuhkan pelayanan dari pemerintah, pandangan ini seharusnya dapat dihilangkan untuk dapat meningkatkan pelayanan public (Eko Widodo, Noor Cholidah, Putri Isnaeni, Tri Wibowo, \& Abriandi, 2019)(Probosiwi, 2016). Sehingga penyelenggaraan pelayanan public yang ada bagi masyarakat dapat ditingkatkan pada semua kantor atau dinas yang terkait dengan pelayanan public (Mardiyanto \& Ismowati, 2018)(Eko Widodo et al., 2019). 
Terkait dengan tugas pokok yang harus dilaksanakan sebagai bentuk pelayanan kepada masyarakat maka berkualitas tidaknya suatu pelayanan yang diberikan oleh birokrasi sebagai penyedia layanan pada akhirnya berdampak pada kepuasan warga atau masyarakat sebagai pengguna layanan (Putra, Pratiwi, \& Trisnawati, n.d.)(Sartini, Minarsih, \& Wulan, 2016)(Tamara, Mananeke, \& Kojo, 2018).

Untuk itu menjadi penting dilakukan analisis yang terkait dengan pelayanan public untuk mewujudkan kualitas pelayanan yang berdampak pada kepuasan masyarakat sebagai pengguna layanan, dengan tujuan dapat diketahui apa yang perlu adanya perubahan atau perbaikan sistem penyelenggaraan pelayanan yang ada di birokrasi pemerintah seperti yang ada di Kantor Desa Paulan Kecamatan Colomadu Kabupaten Karanganyar. Hal ini dilakukan dalam upaya untuk memenuhi harapan akan kebutuhan pelayanan public.

\section{LANDASAN TEORI}

\section{A. 1. Pelayanan Publik}

Pelayanan public merupakan bentuk pelayanan untuk kepentingan masyarakat yang dilakukan oleh organisasi non profit (Sinambela, 2006). Selain itu sebagai pemberian layanan (melayani) keperluan orang atau masyarkat yang mempunyai kepentingan pada organisasi itu sesuai dengan aturan pokok dan tata cara yang telah ditetapkan(Pasolong Harbani, 2007)(Sinambela, 2012).

\section{Kualitas Pelayanan Publik}

Kualitas mengandung banyak pengertian, antara lain kesesuaian dengan persyaratan, kecocokan dengan pemakaian, perbaikan berkelanjutan, bebas dari kerusakan atau cacat, memenuhi kebutuhan pelanggan sejak awal dan setiap saat, melakukan segala sesuatu dengan benar dan sesuatu yang bisa membahagiakan pelanggan.(H.A., 2008).

\section{Kepuasan Masyarakat}

Kepuasan merupakan fungsi dari kesan kinerja dan harapan. Jika kinerja berada dibawah harapan harapan, pelanggan tidak puas. Umumnya harapan dan seseorang merupakan perasaan atau keyakinan tentang apa yang akan diterimanya bila ia membeli atau mengkonsumsi suatu produk (barang atau jasa)(Ali \& Widyasari, 2013).

\section{Kerangka Pemikiran}

Aspek yang diukur pada penelitian ini dari beberapa aspek penilaian seperti : aspek ketepatan waktu pelayanan, akurasi pelayanan, kesopanan dan keramahan, kemudahan untuk mendapatkan pelayanan, kenyamanan dan keamanan, serta atribut pendukung pelayanan yang lain. Sesuai dengan uraian tersebut maka dapat digambarkan kerangka pemikiran dalam penelitian ini ditunjukkan pada Gambar 2.1.

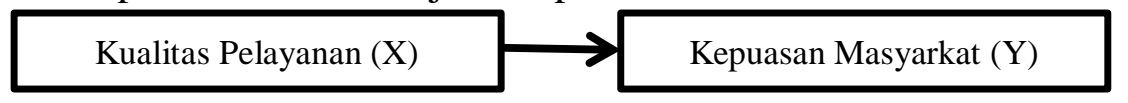

Gambar 2.1. Kerangka pemikiran

\section{Hipotesis}

Hipotesis yang dirumuskan dalam penelitian ini yaitu sebagai berikut: Diduga terdapat pengaruh yang signifikan antara kualitas pelayanan Kantor Desa terhadap 
kepuasan masyarakat pada Kantor Desa Paulan Kecamatan Colomadu Kabupaten Karanganyar.

\section{METODOLOGI PENELITIAN}

Metode penelitian yang digunakan dalam penelitian menggunakan pendekatan kuantitatif. Dengan jenis penelitian eksplanatif (eksplanatory research). Adapun desain penelitian yang digunakan adalah desain penelitian kausal. Dalam penelitian ini bertujuan untuk mengetahui hubungan atau pengaruh dari variable kualitas pelayanan terhadap kepuasan masyarakat pada pelayanan Kantor Desa Paulan kecamatan Colomadu Kabupaten Karanganyar.

\section{Lokasi Penelitian}

Lokasi penelitian di Kantor Desa Paulan Kecamatan Colomadu Kabupaten Karanganyar.

\section{Metode Pengambilan Sampel}

a. Besarnya populasi

Populasi dalam penelitian ini adalah semua masyarakat yang menggunakan layanan di Kantor Desa Paulan Kecamatan Colomadu Kabupaten Karanganyar. Adapun rata-rata masyarakat yang meminta layanan adalah sebanyak 327 orang.

b. Besarnya sampel

Mengingat jumlah pelayanan dalam satu bulan yang ada di Kecamatan lebih dari 100, maka besarnya sampel yang diambil sebanyak 20\% dari 327 orang, maka diperoleh angka sebesar 65,4 yang dibulatkan menjadi 65 orang.

c. Cara penarikan sampel

Teknik penarikan sampel dalam penelitian ini menggunakan teknik accident sampling dimana setiap populasi yang ditemui oleh peneliti dijadikan sampel dalam penelitian ini.

\section{Teknik Pengumpulan Data}

Teknik pengumpulan data dengan cara memberi seperangkat pertanyaan atau pertanyaan tertulis kepada responden untuk dijawab.

\section{Validitas dan Reliabilitas Data}

a. Validitas data

Untuk menguji digunakan teknik korelasi "Product Moment" (Sugiyono, 2005)

$$
r_{12}=\frac{n \sum x_{i} y_{i}-\left(\sum x_{i}\right)\left(\sum y_{i}\right)}{\sqrt{\left\{n \sum x_{i}^{2}-\left(\sum x_{i}\right)^{2}\right\}\left\{n \sum y_{i}^{2}-\left(\sum y_{i}\right)^{2}\right\}}}
$$

b. Reliabilitas

Untuk mengetahui reliabilitas angket digunakan rumus Alpha Cronbach seperti ditunjukkan pada persamaan 3.2 berikut, (Purbayu Budi Santosa, 2007)

$$
r 11=\left\{\frac{k}{i-1}\right\}\left\{1-\frac{\sum \sigma b^{2}}{\sigma t^{2}}\right\}
$$

\section{Teknik Analisis Data}

a. Regresi linier 
Metode analisis yang digunakan adalah regresi linier berganda (Sugiyono, 2011), ditunjukkan pada persamaan 3.3,

$\mathrm{Y}=\mathrm{a}+\mathrm{bX}+\mathrm{e}$

Dengan $\mathrm{Y}=$ kepuasan masyarakat, $\mathrm{a}=$ konstanta, $\mathrm{b}=$ koefisien regresi, $\mathrm{X}=$ kualitas pelayanan, $\mathrm{e}=$ tingkat kesalahan.

b. Uji Hipotesis dengan Uji $\mathrm{t}$

Uji $\mathrm{t}$ digunakan untuk menguji dugaan hipotesis yang telah ditetapkan sebelumnya tentang pengaruh variable independen terhadap variable dependen dengan ketentuan sebagai berikut:

Ho diterima apabila nilai sig $>0,05$ atau nilai $-\mathrm{t}_{\text {tabel }} \leq \mathrm{t}_{\text {hitung }} \leq \mathrm{t}_{\text {tabel }}$

Ho ditolak apabila nilai sig $<0,05$ atau nilai $\mathrm{t}_{\text {hitung }}>\mathrm{t}_{\text {tabel }}$ atau $\mathrm{t}_{\text {hitung }}<-\mathrm{t}_{\text {tabel }}$

c. Koefisien Determinasi $\left(\mathrm{R}^{2}\right)$

Koefisien determinasi digunakan untuk mengukur proporsi/presentasi sumbangan dari variable independen terhadap variable dependen yang terdapat dalam model regresi.

\section{HASIL PENELITIAN}

Karakteristik responden berdasarkan umur dapat diketahui bahwa jumlah responden dengan usia kurang dari 20 tahun terdapat 17 responden $(26,1 \%)$, yang berumur antara 21-40 tahun terdapat 41 responden $(63,2 \%)$ sedangkan yang berumur lebih dari 40 tahun terdapat 7 responden $(10,7 \%)$. Karakteristik umum responden berdasarkan jenis kelamin dapat diketahui bahwa jumlah responden yang mempunyai jenis kelamin laki-laki terdapat 44 responden $(67,7 \%)$ dan responden dengan jenis kelamin perempuan terdapat 21 responden $(23,3 \%)$.

Karakteristik berdasarkan pekerjaan dapat ditunjukkan pada Tabel 1,

TABEL 1 KARAKTERISTIK RESPONDEN BERDASARKAN PEKERJAAN

\begin{tabular}{|c|c|c|}
\hline Pekerjaan & Frekuensi & Persentase \\
\hline Petani & 22 & $33,8 \%$ \\
Wiraswasta & 9 & $13,8 \%$ \\
Profesional & 2 & $3,1 \%$ \\
PNS & 25 & $38,5 \%$ \\
Polri/TNI & 7 & $10,8 \%$ \\
\hline Jumlah & 65 & $100 \%$ \\
\hline
\end{tabular}

Sumber : Hasil pengolahan data primer

Karakteristik berdasarkan keperluan terhadap pelayanan kantor Desa dapat ditunjukkan pada Tabel 2,

TABEL 2 KARAKTERISTIK RESPONDEN BERDASARKAN KEPERLUAN TERHADAP PELAYANAN KANTOR DESA

\begin{tabular}{|c|c|c|}
\hline Keperluan & Frekuensi & Persentase \\
\hline Kartu Keluarga & 15 & $23,1 \%$ \\
KTP & 43 & $66,1 \%$ \\
Surat Izin & 7 & $10,8 \%$ \\
\hline Jumlah & 65 & $100 \%$ \\
\hline
\end{tabular}

Sumber : Hasil pengolahan data primer 
Hasil analisa data untuk uji instrument penelitian, dari hasil pengujian validitas dari 10 item pertanyaan menggunakan teknik one shot methods yaitu dengan membandingkan $\mathrm{r}_{\text {_hitung }}$ dengan $\mathrm{r}_{\text {_tabel }}$ dapat ditunjukkan pada Tabel 3,

TABEL 3 UJI VALIDITAS UNTUK VARIABEL KUALITAS PELAYANAN

\begin{tabular}{|c|c|c|c|}
\hline Item Pertanyaan & $\mathrm{r}_{\text {item }}$ & $\mathrm{r}_{\text {tabel }}$ & Keterangan \\
\hline P1 & 0,557 & 0,240 & Valid \\
P2 & 0,408 & 0,240 & Valid \\
P3 & 0,426 & 0,240 & Valid \\
P4 & 0,555 & 0,240 & Valid \\
P5 & 0,557 & 0,240 & Valid \\
P6 & 0,565 & 0,240 & Valid \\
P7 & 0,325 & 0,240 & Valid \\
P8 & 0,446 & 0,240 & Valid \\
P9 & 0,492 & 0,240 & Valid \\
P10 & 0,491 & 0,240 & Valid \\
\hline
\end{tabular}

Sumber : Hasil pengolahan data primer

Dari Tabel 4 dapat dijelaskan korelasi item-item pertanyaan terhadap variable yang mempunyai nilai $r_{\text {item }}$ lebih besar dari $r_{\text {tabel }}$ sehingga hasil dapat dinyatakan semua pertanyaan valid. Dari hasil pengujian variable produk dari 8 item pertanyaan menggunakan teknik one shot methods, didapatkan hasil yang ditunjukkan pada Tabel 6,

TABEL 4 UJI VALIDITAS UNTUK VARIABEL KEPUASAN MASYARAKAT

\begin{tabular}{|c|c|c|c|}
\hline Item Pertanyaan & $\mathrm{r}_{\text {item }}$ & $\mathrm{r}_{\text {tabel }}$ & Keterangan \\
\hline P1 & 0,248 & 0,240 & Valid \\
P2 & 0,288 & 0,240 & Valid \\
P3 & 0,769 & 0,240 & Valid \\
P4 & 0,789 & 0,240 & Valid \\
P5 & 0,668 & 0,240 & Valid \\
P6 & 0,651 & 0,240 & Valid \\
P7 & 0,752 & 0,240 & Valid \\
P8 & 0,747 & 0,240 & Valid \\
\hline
\end{tabular}

Sumber : Hasil pengolahan data primer

Dari Tabel 4 dapat dijelaskan korelasi item-item pertanyaan terhadap variable yang mempunyai nilai $r_{i t e m}$ lebih besar dari $r_{\text {tabel }}$ sehingga hasil dapat dinyatakan semua pertanyaan valid. Hasil uji reliabilitas untuk semua variable dalam penelitian dapat ditunjukkan pada Tabel 5,

TABEL 5 HASIL UJI RELIABILITAS

\begin{tabular}{|c|c|c|c|}
\hline Variabel & Alpha Cronbach & Kriteria & Keterangan \\
\hline Kualitas Pelayanan & 0,636 & Alpha Cronbach $>$ & Reliabel \\
Kepuasan Masyarakat & 0,776 & 0,60 maka reliabel & Reliabel \\
\hline
\end{tabular}

Sumber : Hasil pengolahan data primer 
Berdasarkan Tabel 5, dapat diketahui bahwa semua instrument yang digunakan untuk variable dalam penelitian ini reliabel sehingga instrument dapat digunakan sebagai alat unuk mengukur variable dalam penelitian.

Hasil uji regresi linier berganda dapat ditunjukkan pada Tabel 6 ,

TABEL 6 HASIL UJI REGRESI LINIER BERGANDA

\begin{tabular}{|c|c|c|c|c|c|c|}
\hline \multirow{2}{*}{\multicolumn{2}{|c|}{ Variabel }} & \multicolumn{2}{|c|}{ Unstandardized Coefficients } & \multirow{2}{*}{$\begin{array}{c}\text { Standardized } \\
\text { Coefficients } \\
\text { Beta }\end{array}$} & \multirow[b]{2}{*}{$\mathrm{t}$} & \multirow[b]{2}{*}{ Sig. } \\
\hline & & B & Std.Error & & & \\
\hline \multirow[t]{2}{*}{1} & (Constant) & -4.635 & 4.377 & & -1.059 & .294 \\
\hline & Kualitas Pelayanan & .835 & .111 & .689 & 7.542 & .000 \\
\hline
\end{tabular}

a.Dependent Variable : Kepuasan Masyarakat

$$
\mathrm{Y}=-4,635+0,835 \mathrm{X}
$$

Diketahui bahwa $\alpha=-4,635$ dan $b=0,835$, artinya nilai $\alpha($ konstan $)=-4,635$, bernilai negative artinya apabila tidak terdapat variable kualitas pelayanan akan dapat menurunkan kepuasan masyarakat pada pelayanan yang ada di Kantor Desa Paulan Kecamatan Colomadu Kabupaten Karanganyar. Nilai $b=0,835$ bernilai positif artinya kualitas pelayanan mempunyai pengaruh terhadap kepuasan masyarakat. Apabila terdapat peningkatan kualitas pelayanan akan dapat berpengaruh terhadap peningkatan kepuasan masyarakat yang ada di Kantor Desa Paulan Kecamatan Colomadu Kabupaten Karanganyar.

Berdasarkan hasil uji hipotesis dengan uji t dalam penelitian ini diperoleh nilai $\mathrm{t}_{\text {hitung }}$ sebesar 7,542 dengan tingkat signifikansi sebesar 0,000. Sehingga dapat diketahui bahwa nilai $t_{\text {hitung }}$ lebih besar dari nilai $t_{\text {tabel }}(7,542>1,998)$ dan signifikasi lebih kecil dari 0,05 $(0,000<0,05)$.

Dari hasil analisis dapat ditarik kesimpulan bahwa dengan $t_{\text {hitung }}$ lebih besar dari nilai $\mathrm{t}_{\text {tabel }}(7,542>1,998)$ dan signifikasi lebih kecil dari $0,05(0,000<0,05)$ maka kualitas pelayanan mempunyai pengaruh terhadap kepuasan masyarakat yang menggunakan pelayanan di Kantor Desa Paulan Kecamatan Colomadu Kabupaten Karanganyar.

Hasil dari uji koefisien determinasi dalam penelitian ini diperoleh nilai $\mathrm{R}^{2}$ sebesar 0,474 . Sehingga dapat diketahui bahwa proporsi pengaruh kualitas pelayanan terhadap kepuasan masyarakat sebesar $47,4 \%$, sedangkan sisanya sebesar $52,6 \%$ dipengaruhi oleh variable lain selain kualitas pelayanan.

\section{KESIMPULAN}

Hasil penelitian berdasarkan analisa yang telah dilakukan tentang pengaruh kualitas pelayanan terhadap kepuasan masyarakat yang menggunakan pelayanan di Kantor Desa Paulan Kecamatan Colomadu Kabupaten Karanganyar, dapat ditarik kesimpulan bahwa kualitas pelayanan yang menyangkut aspek ketepatan waktu dalam pelayanan, akurasi dalam pelayanan, kesopanan dan keramahan pegawai serta kenyamanan terbukti mempunyai pengaruh yang positif dan signifikan terhadap kepuasan masyarakat yang menggunakan pelayanan yang ada di Kantor Desa Paulan Kecamatan Colomadu Kabupaten Karanganyar. Hal ini dapat dilihat dari besarnya $t_{\text {tabel }}(7,542>1,998)$ dan signifikansi lebih kecil dari 0,05 $(0,000<0,05)$.

Proporsi pengaruh kualitas pelayanan terhadap kepuasan masyarakat yang menggunakan pelayanan yang ada di Kantor Desa Paulan Kecamatan Colomadu Kabupaten 
Karanganyar sebesar 47,4\%, sedangkan sisanya sebesar 52,6\% dipengaruhi oleh variable lain selain kualitas pelayanan seperti keberadaan kantor, sarana dan prasarana penunjang pelayanan dan sebagainya.

\section{UCAPAN TERIMA KASIH}

Terimakasih kepada segenap masyarakat yang ada di Desa Paulan Kecamatan Colomadu Kabupaten Karanganyar yang sudah banyak membantu dalam penelitian ini.

Terimakasih kepada Bapak Lurah dan segenap pegawai Desa Paulan Kecamatan Colomadu Kabupaten Karanganyar yang telah membantu dan mendukung sepenuhnya dalam penelitian ini.

\section{DAFTAR PUSTAKA}

Ali, M., \& Widyasari, R. (2013). Teori dan Model Pengukuran Kepuasan Masyarakat terhadap Keberkesanan Sistem Pelayanan Publik. Tingkap, IX(2).

Egaliter, J. (2019). Efektivitas Peran Public Relations Petugas Pelayanan Pada Kepuasan Masyarakat Desa Leyangan Kecamatan Ungaran Timur Kabupaten Semarang. 3(5), 68-89.

Eko Widodo, W., Noor Cholidah, S., Putri Isnaeni, A., Tri Wibowo, K., \& Abriandi, E. (2019). Mengukur Kepuasan Masyarakat Pada Program CSR di Desa Kertajaya: Sebuah Analisis Menggunakan Metode Sustainability Compass. Jurnal Pemberdayaan Masyarakat: Media Pemikiran Dan Dakwah Pembangunan, 3(1), 29-52. https://doi.org/10.14421/jpm.2019.031-02

H.A., I. (2008). Teori dan konsep pelayanan publik serta implementasinya. CV Mandar Maju.

Hardiyansyah. (2018). Kualitas Pelayanan Publik: Konsep, dimensi, Indikator dan Implementasinya. Yogyakarta: Gava Media.

Hermawan, W., Hakim, D. B., \& Hutagaol, M. P. (2016). Analisis Kepuasan Masyarakat terhadap Kualitas Pelayanan dalam Pendaftaran Tanah Pertama kali Pada Kantor Pertanahan Kabupaten Bogor. Jurnal Ilmu Keluarga Dan Konsumen, 9(1), 65-75. https://doi.org/10.24156/jikk.2015.9.1.65

Izudin, A. (2019). Kepuasan masyarakat terhadap pelayanan publik dalam mewujudkan good governance di Kecamatan Umbulharjo Kota Yogyakarta. Publisia: Jurnal Ilmu Administrasi Publik, 4(1). https://doi.org/10.26905/pjiap.v4i1.2199

Jayanti, S. D., Perkantoran, P. A., Ekonomi, F., Yogyakarta, U. N., \& Masyarakat, I. K. (2018). Kepuasan Masyarakat Terhadap Pelayanan Administrasi Terpadu Di Kantor Kecamatan Umbulharjo Yogyakarta. 777, 777-786. 
Lembaga, K., Negara, A., Penyelenggaraan, P., Dan, P., \& Publik, P. (2011). Peraturan Kepala Lembaga Administrasi Negara Nomor 10 Tahun 2011.

Mardiyanto, R., \& Ismowati, M. (2018). Analisis Indeks Kepuasan Masyarakat Dalam Upaya Peningkatan Kepuasan Kualitas Pelayanan Masyarakat Di Kantor Kecamatan Kotabaru Kabupaten Karawang. Transparansi Jurnal Ilmiah Ilmu Administrasi, 9(2), 184-197. https://doi.org/10.31334/trans.v9i2.23

Mørk, G., Magne, T. A., Carstensen, T., Stigen, L., Åsli, L. A., Gramstad, A., ... Bonsaksen, T. (2020). Associations between learning environment variables and students' approaches to studying: a cross-sectional study. BMC Medical Education, 20(1), 120. https://doi.org/10.1186/s12909-020-02033-4

Pasolong Harbani. (2007). Teori Administrasi Publik. Bandung: Alfabeta.

Pendayagunaan, M., \& Negara, A. (2004). Keputusan Menteri Pemberdayaan Aparatur Negara Nomor 63 Tahun 2003 Tentang Pedoman Umum Penyelenggaraan Pelayanan Publik. 1-8.

Probosiwi, R. (2016). Tanggung Jawab Sosial Perusahaan dalam Peningkatan Kesejahteraan Masyarakat (Corporate Social Responsibility in Public Welfare Enhancement). SOCIA: Jurnal Ilmu-Ilmu Sosial, 13(2). https://doi.org/10.21831/socia.v13i2.12256

Purbayu Budi Santosa, M. H. (2007). Statistika Deskriptif dalam Bidang Ekonomi dan Niaga. Jakarta: Erlangga.

Putra, D. G., Pratiwi, R. N., \& Trisnawati. (n.d.). Pengaruh Kualitas Pelayanan Terhadap Kepuasan Masyarakat (Studi pada Dinas Kependudukan dan Pencatatan Sipil Kota Blitar). Jurnal Administrasi Publik (JAP), 3(12), 2118-2122.

Restianti, A. (2018). Evaluasi Pelayanan Kesehatan Dan Pendidikan Program Keluarga Harapan (Pkh). Jurnal Pemberdayaan Masyarakat: Media Pemikiran Dan Dakwah Pembangunan, 1(2), 423. https://doi.org/10.14421/jpm.2017.012-10

Sains, S. N., Penelitian, L., Pengabdian, D. A. N., \& Uit, M. (2019). Seminar nasional sains, teknologi, dan sosial humaniora uit 2019.

Sartini, U., Minarsih, M. M., \& Wulan, H. S. (2016). Faktor-Faktor Yang Mempengaruhi Kepuasan Masyarakat Dalam Pengurusan Kartu Identitas Penduduk (Ktp-El) Dan Dokumen Kependudukan Di Kantor Dinas Kependudukan Dan Pencatatan Sipil Kota Semarang. Journal of Management, 2(2), 110.

Sinaga, J., \& Hidayat, R. (2016). Pengaruh Kualitas Pelayanan Terhadap Kepuasan Masyarakat Dalam Pelaksanaan Program Pelayanan Administrasi Terpadu Kecamatan. Jurnal Akuntansi, Ekonomi Dan Manajemen Bisnis, 4(1), 7-14. 
Sinambela, L. P. (2006). Reformasi dalam Pelayanan Publik. Jakarta: PT. Bumi Aksara.

Sinambela, L. P. (2012). Kinerja Pegawai Teori Pengukuran dan Implikasi. Yogyakarta: Graha Ilmu.

Sugiyono. (2005). Metode Penelitian Bisnis. Yogyakarta: Alfa Beta.

Sugiyono. (2011). Statistika untuk Penelitian. Bandung: Alfabeta.

Sukma, M. (2015). Analisis Pengaruh Kualitas Pelayanan Terhadap Kepuasan Masyarakat (Studi Kantor Kelurahan Tempurejo Kecamatan Pesantren Kota Kediri ). 04(September), 80-88. https://doi.org/10.1017/CBO9781107415324.004

Tamara, N. I. ., Mananeke, L., \& Kojo, C. (2018). Minahasa Selatan the Effect of Service Quality Against Kawangkoan Communities Under Kecamatan Amurang Barat in Minahasa Selatan District. Jurnal Emba, 6(4), 3523-3532.

Wardani, tri ulfa. (2017). Pengaruh Kulaitas Pelayanan Terhadap Kepuasan Konsumen Pada Bisnis jasa Transportasi Gojek.

www.dpr.go.id. (2004). Undang-Undang No 32 Tahun 2004 Tentang Pemerintah Daerah. Dpr, 249.

Yayat, R. (2017). Kualitas Pelayanan Publik Bidang Administrasi Kependudukan Di Kecamatan Gamping. Jurnal Ilmiah Magister Ilmu Administrasi (JIMIA), (2), 56-65. 